\title{
Maternal dyslipidaemic diet induces sex-specific alterations in intestinal function and lipid metabolism in rat offspring
}

\author{
Rafael Oliveira Pinheiro ${ }^{1}$, Priscilla Paulo Lins ${ }^{1}$, Jader Luciano Pinto de Carvalho ${ }^{1}$, \\ Emmanuel Veríssimo de Araújo ${ }^{1}$, Adriano Francisco Alves ${ }^{2}$, Ramon de Alencar Pereira ${ }^{3}$, \\ Lydiane Tavares Toscano ${ }^{4}$, Alexandre Sérgio Silva ${ }^{4}$, Evandro Leite de Souza ${ }^{5}$, José Luiz de Brito Alves ${ }^{1}$ \\ and Jailane de Souza Aquino ${ }^{1 *}$ \\ ${ }^{1}$ Laboratório de Nutrição Experimental, Departamento de Nutrição, Universidade Federal da Paraíba (UFPB), João Pessoa, \\ 58051-900, Paraíba, Brazil \\ ${ }^{2}$ Laboratório de Patologia, Departamento de Fisiologia e Patologia, Universidade Federal da Paraíba (UFPB), João Pessoa, \\ 58051-900, Paraíba, Brazil \\ ${ }^{3}$ Laboratório de Patologia, Departamento de Patologia, Universidade Federal de Minas Gerais (UFMG), Belo Horizonte, \\ 31270-901, Minas Gerais, Brazil \\ ${ }^{4}$ Laboratório de Estudos do Treinamento Físico Aplicado ao Desempenho e a Saúde, Departamento de Educação Física, \\ Universidade Federal da Paraíba (UFPB), João Pessoa, 58051-900, Paraíba, Brazil \\ ${ }^{5}$ Laboratório de Microbiologia de Alimentos, Departamento de Nutrição, Universidade Federal da Paraíba (UFPB), \\ João Pessoa, 58051-900, Paraíba, Brazil
}

(Submitted 20 June 2018 - Final revision received 20 December 2018 - Accepted 30 December 2018 - First published online 23 January 2019)

\section{Abstract}

This study investigated the effects of a maternal dyslipidaemic (DLP) diet on lipid metabolism, microbial counts in faeces and hepatic and intestinal morphology in rat offspring with respect to sex during different phases of life. Wistar rats (dams) were fed a control (CTL) or DLP during gestation and lactation. After weaning, CTL and DLP offspring were fed a standard diet. The effects of a maternal DLP on body composition, biochemical parameters, faecal microbiota and intestinal and hepatic histomorphometric characteristics in rat offspring were evaluated at 30 and $90 \mathrm{~d}$ of age. The DLP diet during gestation and lactation caused lower birth weight and a greater weight gain percentage at the end of the $90-\mathrm{d}$ period in both male and female offspring. Female pups from DLP dams had higher liver fat levels compared with CTL $(P \leq 0 \cdot 001)$ at $90 \mathrm{~d}$ of age. Males from DLP dams had greater visceral fat weight and lower Lactobacillus spp. faecal counts at $90 \mathrm{~d}$ of age $(P \leq 0 \cdot 001)$ as well as lower faecal fat excretion $(P \leq 0.05)$ and Bacteroides spp. faecal counts $(P \leq 0 \cdot 001)$ at $30 \mathrm{~d}$ of age when compared with pups from CTL dams. However, both dams and DLP pups showed damage to intestinal villi. A maternal DLP alters intestinal function and lipid metabolism in a sex-specific manner and is a potential predisposing factor for health complications in offspring from the juvenile period to the adult period.

Key words: Dyslipidaemic diets: Lipid metabolism: Intestinal microbiota: Pups

Dietary habits and Western lifestyles have been studied because they may be the influential factors for a variety of metabolic diseases $^{(1-3)}$. The consumption of diets with high energy density and high levels of fat, cholesterol and saturated and transfatty acids has been associated with several metabolic disorders, such as dyslipidaemia, which are the main risk factors for $\operatorname{CVD}^{(4,5)}$.

Dyslipidaemia, which is characterised by altered levels of circulating lipids and lipoproteins in organisms, may have a genetic or environmental aetiology and mainly affects sedentary individuals with inadequate eating habits ${ }^{(6)}$. These changes in lipid levels may also affect pregnant women and infants, by whom predisposition to disease may be acquired before or during pregnancy ${ }^{(7)}$ as well as be a consequence of maternal overweight $^{(8,9)}$.

Although the modulation of gut microbiota in newborns has been believed to occur through breast-feeding and the inclusion of other foods in the post-weaning diet, there has been strong evidence indicating that the gut colonisation of infants may have already occurred before birth ${ }^{(10-12)}$. Dyslipidaemia may promote intestinal villi wear and in the long-term, alterations in gut microbiota composition ${ }^{(13-15)}$. Populations of

Abbreviations: CTL, control; DLP, dyslipidaemic; TC, total cholesterol.

* Corresponding author: J. de Souza Aquino, email aquinojailane@gmail.com, jailane@ccs.ufpb.br 
Enterococcus spp., Lactobacillus spp. and Bifidobacterium spp. have been positively associated with HDL serum levels and negatively associated with total cholesterol (TC), LDL and VLDL-cholesterol serum levels as well as with the extension of atherosclerotic lesions ${ }^{(16)}$.

The available literature reports remarkable sensitivity of the offspring to nutritional, hormonal and environmental changes in both the prenatal and postnatal periods, modulating the risk for the development of metabolic diseases in adulthood ${ }^{(17,18)}$. Diet has been considered an important influential factor in the health/disease state ${ }^{(19,20)}$. Although the mechanisms are not fully understood, previous studies have suggested that metabolic dysfunction in adult offspring exposed to nutritional insults during early life may be sex-specific ${ }^{(21-23)}$. Primarily, this sex difference has been related to female hormones, which are thought to protect against the development of metabolic disorders $^{(20,24)}$

Some studies have been performed using rats to ascertain the effect of maternal diets and treatments on the offspring ${ }^{(25,26)}$, being

a well-recognised and widely used experimental model, considering the levels of evidence in health and scientific investigations ${ }^{(27)}$. Based on the fact that high levels of saturated fats and cholesterol may be harmful to the body, this study investigated whether the consumption of a dyslipidaemic diet affects the lipid metabolism, microbial counts in faeces and intestinal and hepatic morphology of dams during pregnancy and lactation as well as of their male and female pups from lactation to adulthood, since previous studies are limited to the follow-up of male pups of a preestablished age and usually without follow-up of the potential changes in different life phases.

\section{Methods}

\section{Animals and experimental design}

The experimental protocol was submitted and approved by the institutional animal care and use committee (CEUA-UFPB protocol 017/2017) of Federal University of Paraíba (Brazil). All experiments were carried out in agreement with the guidelines of the Brazilian Society of Science in Laboratory Animals (SBCAL).

All animals used in the experiment received water and diet ad libitum and were maintained at a temperature of $21 \pm 1^{\circ} \mathrm{C}$, with humidity between 50 and $55 \%$ and a 12-h alternation of light-dark cycles. Primiparous Wistar (Rattus norvegicus) rats $\pm 90 \mathrm{~d}$ of age and weighing over $200 \mathrm{~g}(n$ 12) were mated to $4: 1$ fertile male rats $(n 3)$. The presence of sperm in the vaginal smear was used to define the 1st day of pregnancy. Subsequently, the dams were placed in single cages and randomly allocated into two groups: control (CTL, $n$ 6) and dyslipidaemic (DLP, $n$ 6). The CTL group was fed a CTL diet for growth with soyabean oil as the fat source (AIN-93G; $15.92 \%$ fat) ${ }^{(28)}$, and the DLP group was fed a dyslipidaemic diet with $31 \cdot 11 \%$ fat, containing soyabean oil, cholesterol, lard and non-hydrolysed vegetable fat as fat sources (Tables 1 and 2).

After the determination of pregnancy, the body weight of dams was measured weekly. Food intake during gestation (time G0, G1, G2 and G3) and lactation (time L0, L1, L2 and L3) was
Table 1. Composition of control and dyslipidaemic diets offered to dams during pregnancy and lactation (AIN-93G)

\begin{tabular}{lcc}
\hline & \multicolumn{2}{c}{ Diets } \\
\cline { 2 - 3 } Ingredients $(\mathrm{g} / 100 \mathrm{~g})$ & Control (AIN-93G) & Dyslipidaemic \\
\hline Maize starch & 39.75 & 33.09 \\
Dextrinised maize starch & 13.20 & 15.50 \\
Casein & 20.00 & 19.86 \\
Sucrose & 10.00 & 6.00 \\
Soyabean oil & $7 \cdot 00$ & 3.00 \\
Animal fat (lard) & - & 6.00 \\
Non-hydrolysed vegetable fat & - & 5.00 \\
Sigma cholesterol & - & 1.00 \\
Sigma colic acid & - & 0.50 \\
Fibre & 5.00 & 5.00 \\
Mineral mix 93G & 3.50 & 3.50 \\
Vitamin mix & 1.00 & 1.00 \\
L-Cystine & 0.30 & 0.30 \\
Choline bitartrate & 0.25 & 0.25 \\
$t$-BHQ & 0.014 & 0.014 \\
Total energy value (kJ/g) & 16.57 & 18.16 \\
Carbohydrates (kJ \%) & 63.58 & 50.32 \\
Proteins (kJ \%) & 20.20 & 20.06 \\
Lipids (kJ \%) & 15.91 & 31.82 \\
\hline
\end{tabular}

$t$-BHQ, tert-butylhydroquinone.

* Adapted from Reeves et al. ${ }^{(28)}$

† Rhoster - Industry and Trade Ltd.

also measured. After birth, the weight of the litters (weight of pups divided by the number of pups), number of pups per dam and sex were assessed.

On the 2nd day of life, the pups were reduced to eight per litter (four males and four females) ${ }^{(26)}$. After weaning, on the 21st day of life, all pups were separated by sex and group in box-type group housing and were fed a commercial diet (Presence Purina ${ }^{\oplus}$ ) and water ad libitum. Body weight and food intake of dams and pups were measured weekly during the experimental period using a digital electronic scale (prix III; Toledo). Lipid and total energy intake were calculated based on the composition of the diet consumed by the groups. Euthanasia and collection of faeces, blood, the liver and the intestines were performed after lactation for dams and on the 30th and 90th day of life for the pups during the light phase (online Supplementary Fig. S1).

\section{Fat and microbial counts in faeces}

Faecal samples were collected on the three consecutive days before euthanasia for quantification of excreted fat or counting of the faecal microbiota population in both dams and offspring on the 30th and 90th days. Part of the faecal samples from dams and pups was used to quantify total lipids by cold extraction using a previously described procedure ${ }^{(29)}$. The other part of the faecal samples was homogenised in peptone water $(100 \mathrm{mg} / \mathrm{ml})$ and serially diluted in the same diluent. In all, $20 \mu \mathrm{l}$ aliquots of the respective dilutions were inoculated using a microdrop technique ${ }^{(30)}$ in Bifidobacterium agar (HiMedia) to count Bifidobacterium spp.; agar Man, Rogosa and Sharpe (HiMedia) to count Lactobacillus spp.; agar MacConkey (HiMedia) to count Enterobacteriaceae and agar Bacteroides Bile Esculina (Acumedia) to count Bacteroides spp. (Acumedia). 
Table 2. Fatty acid composition of control and dyslipidaemic diets offered to dams during pregnancy and lactation (AIN-93G) (Mean values and standard deviations)

\begin{tabular}{|c|c|c|c|c|}
\hline \multirow[b]{3}{*}{ Fatty acids (\%) } & \multicolumn{4}{|c|}{ Diets } \\
\hline & \multicolumn{2}{|c|}{ Control (AIN-93G) } & \multicolumn{2}{|c|}{ Dyslipidaemic } \\
\hline & Mean & SD & Mean & SD \\
\hline Capric acid $(C 10: 0)$ & & & 0.03 & 0.01 \\
\hline Lauric acid (C12:0) & 0.05 & 0.01 & 0.12 & 0.00 \\
\hline Myristic acid (C14:0) & $0 \cdot 10$ & 0.01 & 0.99 & 0.02 \\
\hline Pentadecanoic acid (C15:0) & 0.15 & 0.09 & 0.05 & 0.00 \\
\hline Palmitic acid (C16:0) & 12.43 & 0.22 & $26 \cdot 76$ & 0.35 \\
\hline Marginic acid (C17:0) & 0.03 & 0.01 & 0.23 & 0.01 \\
\hline Stearic acid $(\mathrm{C} 18: 0)$ & 3.45 & 0.12 & 8.66 & 0.16 \\
\hline Arachidic acid (C20:0) & 0.40 & 0.01 & 0.31 & 0.01 \\
\hline Behenic acid (C22:0) & & & 0.16 & 0.01 \\
\hline SFA (SFA\%) & $16 \cdot 61$ & 0.50 & 37.31 & 0.57 \\
\hline Palmitoleic acid (C16:1n-7) & 0.15 & 0.05 & 1.02 & 0.02 \\
\hline Heptadecenoic acid (C17:1n-7) & 0.22 & 0.04 & 0.13 & 0.00 \\
\hline Oleic acid (C18:1n-9) & 22.94 & 0.32 & 34.52 & 0.22 \\
\hline Vaccine acid $(C 18: 1 n-11)$ & & & 1.76 & 0.01 \\
\hline Gondoic acid (C20:1n-9) & $0 \cdot 10$ & 0.01 & 0.42 & 0.01 \\
\hline Erucic acid (C22: 1n-9) & 0.08 & 0.01 & 0.19 & 0.04 \\
\hline MUFA (MUFA\%) & 23.49 & 0.45 & 38.04 & 0.30 \\
\hline Linoleic acid (C18:2n-6) & $53 \cdot 35$ & 0.35 & 22.35 & 0.24 \\
\hline$\gamma$-Linolenic acid $(\mathrm{C} 18: 3 n-6)$ & 0.25 & 0.05 & 0.01 & 0.01 \\
\hline$a$-Linolenic acid (C18:3n-3) & $5 \cdot 87$ & 0.21 & 1.74 & 0.04 \\
\hline Eicosadienoic acid (C20:2n-6) & & & 0.32 & 0.01 \\
\hline Dihomo- $\gamma$-linoleic acid $(C 20: 3 n-6)$ & 0.08 & 0.02 & 0.06 & 0.00 \\
\hline cis-Eicosatrienoic acid (C20:3n-3) & 0.32 & 0.08 & 0.15 & 0.00 \\
\hline EPA $(\mathrm{C} 20: 5 n-3)$ & 0.08 & 0.01 & & \\
\hline DHA (C22:6n-3) & 0.11 & 0.00 & 0.06 & 0.00 \\
\hline PUFA (PUFA\%) & 59.90 & 0.71 & 24.65 & 0.30 \\
\hline Ratio (PUFA + MUFA):SFA* & & & & \\
\hline
\end{tabular}

* Adapted from Chalvon-Demersay et al. ${ }^{(27)}$.

Incubation was performed under anaerobic conditions (Anaerobic System Anaerogen; Oxoid Ltd) for counting Bifidobacterium spp., Lactobacillus spp. and Bacteroides spp. and under aerobic conditions for counting Enterobacteriaceae. After an incubation period of $24-48 \mathrm{~h}$, the number of colonies on each selective medium was counted, and the results were expressed as log colony-forming units/g ${ }^{(15)}$

\section{Euthanasia, evaluation of murinometric parameters and quantification of visceral and hepatic fat}

At the end of the pregnancy and lactation period, the dams and eight pups ( $30 \mathrm{~d}$ old) from each group were euthanised. The remaining eight animals were maintained until $90 \mathrm{~d}$ after birth. After $8 \mathrm{~h}$ of fasting, the animals were anaesthetised with intraperitoneal administration of ketamine-xylazine solution ( 75 and $5 \mathrm{mg} / \mathrm{kg}$, respectively) and euthanised by aortic transection.

Murinometric parameters, such as chest circumference (immediately before the hind paw), abdominal circumference (immediately behind the front leg), body weight and naso-anal length, all measured in cm using a metric tape, were evaluated in anaesthetised rats. BMI was calculated using the formula body weight $(\mathrm{g}) /$ length ${ }^{2}\left(\mathrm{~cm}^{2}\right)^{(31)}$ and the Lee index divided by the nasal length $(\mathrm{cm})^{(32)}$.

After euthanasia, the visceral fat was collected for direct weighing on an analytical balance, and its quantification was normalised by the weight of the respective animal. Liver samples were collected for quantification of total lipids using a previously described procedure ${ }^{(29)}$. Samples of liver and intestinal colon were collected, weighed and used for histological analysis.

\section{Lipid profile}

After collection, blood was centrifuged $(58136 \mathrm{~g}$ for $15 \mathrm{~min}$ at $25^{\circ} \mathrm{C}$ ), and the serum was collected for analysis of TC, TAG and HDL, LDL and VLDL. The analyses were performed using commercial kits (Labtest) following the recommendations of manufacturers and an automatic analyser LabMax 240 premium (Labtest) calibrated to read at $505 \mathrm{~nm}$ (TAG), $500 \mathrm{~nm}$ (TC) or $600 \mathrm{~nm}$ (HDL).

\section{Histological evaluation of liver and intestine}

For histological evaluation of the intestine and liver, fragments of the major lobe of the liver and medial portion of the large intestine, viz. the colon $(2 \mathrm{~cm})$, were removed from dams and offspring (30 and $90 \mathrm{~d}$ ), washed in saline solution $(0.9 \% \mathrm{NaCl})$ and fixed in $10 \%$ buffered formalin for $24 \mathrm{~h}$. The tissues were subjected to a histological procedure for obtaining blocks from which semi-serial $4-\mu \mathrm{m}$ sections were cut. The slides were hydrated, stained with haematoxylin-eosin (HE), dehydrated, diaphanised in xylol and mounted with 'entellan' for optical microscopic analysis (Motic BA 200). Hyperaemia, inflammatory exudate, haemorrhage, vasodilation, necrosis, epithelial preservation, hypertrophy and hyperplasia of the smooth muscle 
layer were evaluated in intestinal histological sections ${ }^{(15)}$. Inflammatory exudate, hyperaemia, haemorrhage, necrosis, preservation of the hepatic parenchyma (cell integrity, centralised nuclei and highly evident nucleoli) and degenerative processes (e.g. fat degeneration) were evaluated in liver histological sections ${ }^{(15)}$.

Quantitative analyses of the intestinal morphometry of animals were also performed. Morphometric analyses to quantify the ratio of villus and intestinal crypt using HE were performed using an image analyser with Zeiss Imaging Processing Software (KS 300, Zeiss; licensed to the Department of General Pathology, Institute of Biological Sciences, Federal University of Minas Gerais) ${ }^{(33)}$. From each specimen, twenty-five fields of each histological slide were randomly selected using the 10x objective and captured through the image analyser. In the liver, a semiquantitative analysis was performed by creating a score related to the distribution of the main lesion (i.e. hepatic steatosis) ranging from 0 to 3 , where $0-1$ indicates animal with absence of the lesion; 1-2 indicates discrete lesion distribution (light focal); 2-3 indicates moderate distribution (pronounced focal to diffuse light) and 3-4 indicates sharp (multifocal accentuated to diffuse accentuated). Reading of slides was performed randomly by two pathologists. A $10 \times$ objective and $40 \times$ photomicrograph of the colon and liver were used to obtain the images.

\section{Statistical analysis}

Statistical power of 0.80 ( $80 \%$ ) was obtained by estimating twelve adult female Wistar rats (six females per group), sixteen

(a)

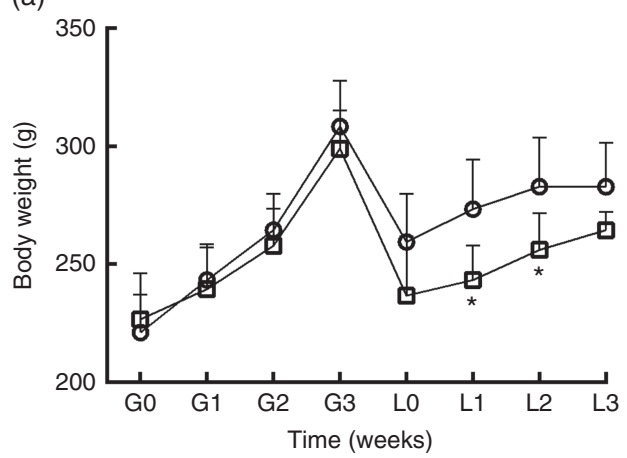

(c)

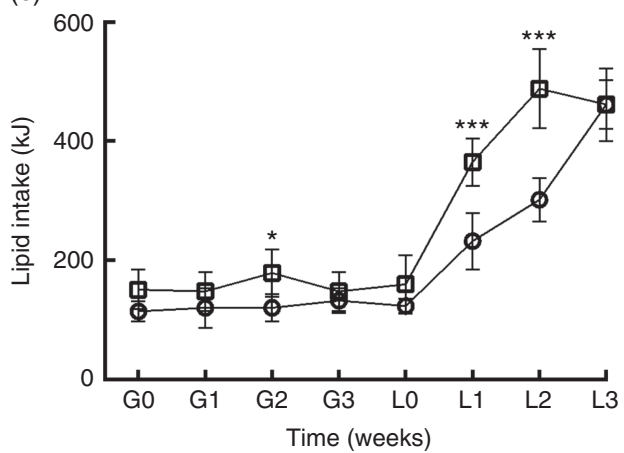

30-d-old pups (eight pups per group) and sixteen 90-d-old pups (eight pups per group). The minimally detectable effect size was $1 \cdot 0$, and the significance level was 0.05. Statistical analyses were performed using GraphPad Prism 6.0 (GraphPad Software Inc.) with the application of two-way repeated-measures ANOVA or Student's $t$ test. For the multiple comparison test between the groups, the Bonferroni post hoc test was used. For correlation analysis, Pearson's correlation test was performed, in which correlations were classified as low $\left(r^{2} 0 \cdot 10-0 \cdot 29\right)$, moderate $\left(r^{2} 0 \cdot 30-0 \cdot 49\right)$, significant $\left(r^{2} 0.5-0.69\right)$ or very high $\left(r^{2} 0 \cdot 70\right)^{(34)}$. A significance level of $5 \%(P \leq 0.05)$ was considered for all tests.

\section{Results}

\section{Food intake and body weight}

DLP dams had lower body weight (Fig. 1(a)) during the lactation period (L1 and L2) $(P \leq 0 \cdot 05)$ compared with the CTL dams. DLP dams also had lower food intake (Fig. 1(b)) during two periods of gestation (G0 and G3) and all lactation period (L1-L3), but no differences were observed in lipid intake between DLP and CTL dams (Fig. 1 (c)) throughout the experiment $(P>0 \cdot 05)$, in spite of the lower total energy intake by DLP dams at L3 time (Fig. $1(\mathrm{~d}))(P \leq 0 \cdot 001)$.

As shown in Fig. 2(a), the pups from DLP dams had low birth weight (LBW) and low weight at $21 \mathrm{~d}$ of age for both sexes $(P \leq 0 \cdot 01)$, but no difference was observed in weight gain at 30 , 60 and $90 \mathrm{~d}$ of age (Fig. 2(b)). Considering the percentage of total weight gain from birth to $90 \mathrm{~d}$ of age (Fig. 2(c)), pups from (b)

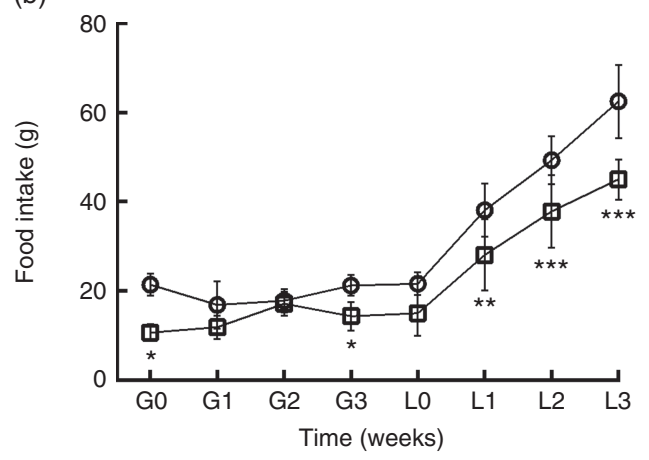

(d)

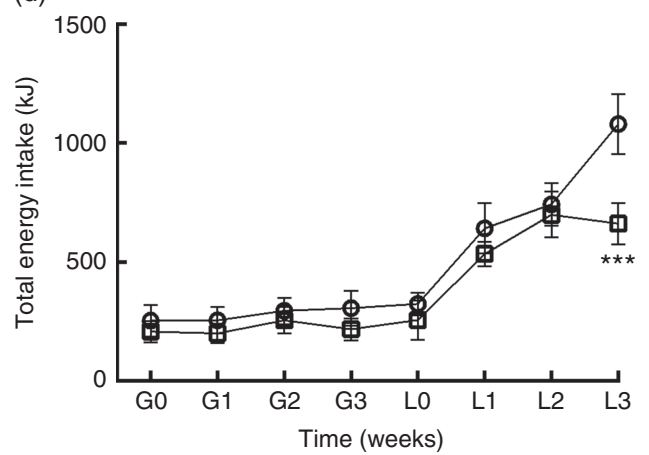

Fig. 1. Body weight (a) of dams that consumed the control (CTL, $-\bigcirc$ ) or dyslipidaemic (DLP, $\square-$ ) diet during pregnancy (G1, G2, G3) and lactation (L1, L2, L3); food intake (b), lipid intake (c) and total energy intake (d). Values are means, with standard deviations represented by vertical bars. ${ }^{*} P \leq 0.05,{ }^{* \star} P \leq 0.01,{ }^{* * *} P \leq 0.001$. Two-way ANOVA followed by Bonferroni post hoc test. 
(a)

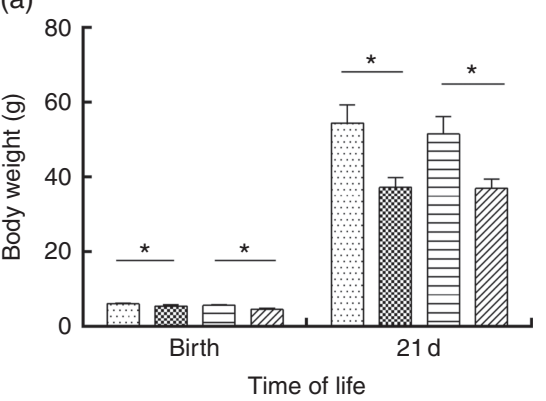

(b)

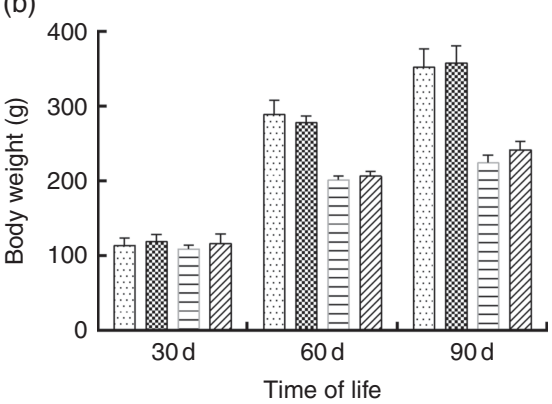

(c)

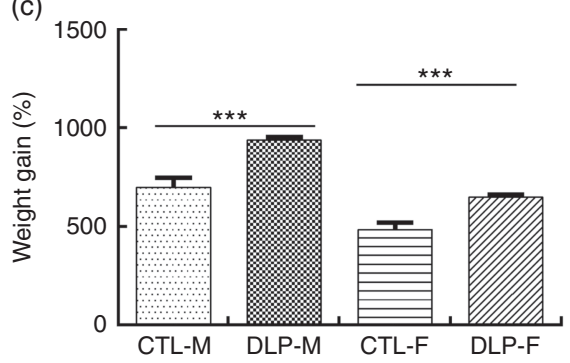

Fig. 2. Body weight of offspring from dams that consumed the control diet (CTL) or dyslipidaemic (DLP) diet at birth, 21st (weaning) (a), 30th, 60th and 90th days of age (b) and total percentage of weight gain (from birth up to the 90th day of age) (c). Values are means, with standard deviations represented by vertical bars. ${ }^{*} P \leq 0.05$, ${ }^{* \star *} P \leq 0.001$. Two-way ANOVA followed by Bonferroni post hoc test. CTL-M (圆), male pups fed by dams that consumed a control diet; DLP-M (R), male pups fed by dams that consumed a dyslipidaemic diet; CTL-F (目), female pups fed by dams that consumed a control diet; DLP-F (四), female pups fed by dams that consumed a dyslipidaemic diet.

DLP dams had a higher percentage of weight gain than pups from CTL dams in both sexes $(P \leq 0.05)$.

\section{Murinometric parameters and organ and tissue weights}

The murinometric parameters of dams measured at the end of the lactation period as well as those of pups at 30 and $90 \mathrm{~d}$ of age were similar for both the CTL and DLP groups $(P>0 \cdot 05)$. Liver weight was higher $(P \leq 0.001)$ in DLP dams than in CTL dams. At $30 \mathrm{~d}$ of age, pups from DLP dams had higher wet weight liver $(P \leq 0.05)$ than pups from CTL dams, but no difference was observed in relative wet weight $(\mathrm{g} / 100 \mathrm{~g})$ of visceral fat or gut, which followed the same pattern seen in the dams. At $90 \mathrm{~d}$ of age, pups of both sexes from DLP dams had higher liver and intestinal weight than pups from CTL dams $(P \leq 0.01)$; however, only males from DLP dams had greater visceral fat weight $(P \leq 0 \cdot 001)$ (Table 3$)$.

\section{Hepatic and faecal fat}

The percentage of liver fat was higher in DLP dams than in CTL dams $(P \leq 0.05)$ (Fig. 3 (a)). In addition, a higher percentage of fat was observed in the liver of pups of both sexes at $30 \mathrm{~d}$ of age whose dams had been fed the DLP diet $(P \leq 0.05)$ (Fig. 3 (c)). However, only female pups from DLP dams at $90 \mathrm{~d}$ of age had higher levels of liver fat $(P \leq 0 \cdot 05)$ than pups from the CTL dams (Fig. 3(c)).

Faecal fat excretion was higher in DLP dams (Fig. 3(a)), and it was lower in male pups from DLP dams at $30 \mathrm{~d}$ of age $(P \leq 0.05)$ when compared with pups from CTL dams (Fig. 3(b)); however, no effect of the diet on faecal fat excretion was observed in pups at $90 \mathrm{~d}$ of age.

\section{Microbial counts in faeces}

Consumption of a dyslipidaemic diet caused a reduction in the counts of Lactobacillus spp. and Bifidobacterium spp. as well as an increase in counts of Bacteroides spp. in faeces of DLP dams after the pregnancy period $(P \leq 0.05)$ compared with those of CTL dams (Fig. 4(a)).

Male and female pups from DLP dams had lower Lactobacillus spp. faecal counts at $30 \mathrm{~d}$ of age compared with pups from CTL dams ( $P \leq 0 \cdot 001)$ (Fig. 4(b)). However, only the male pups from DLP dams presented lower Lactobacillus spp. faecal counts compared with pups from CTL dams at $90 \mathrm{~d}$ of age $(P \leq 0 \cdot 05)$. The lowest faecal counts of Bifidobacterium spp. were observed in male pups from DLP dams either at 30 or $90 \mathrm{~d}$ of age $(P \leq 0.05)$ (Fig. 4(c)).

Male pups from DLP dams had lower faecal counts of Bacteroides spp. than male pups from CTL dams at $30 \mathrm{~d}$ of age ( $P \leq 0.001$ ); however, these counts increased in male pups from DLP dams at $90 \mathrm{~d}$ of age, which were higher than those in male pups from CTL dams $(P \leq 0 \cdot 05)$. Interestingly, these differences were not observed in female pups (Fig. 4(d)). No difference was observed in faecal Enterobacteriaceae counts between groups or sexes at any time points evaluated $(P>0.05)$ (Fig. 4(e)).

\section{Lipid profile}

DLP dams showed higher levels of TC, LDL and TAG compared with CTL dams (Fig. 5(a)). Similarly, higher TAG (Fig. 5(b)) and 
Table 3. Murinometric parameters and normalised weight of organs of dams fed a control diet (CTL) or dyslipidaemic diet (DLP) and of their respective pups at 30 and $90 \mathrm{~d}$ of age

(Mean values and standard deviations)

\begin{tabular}{|c|c|c|c|c|c|c|c|c|}
\hline \multirow{3}{*}{$\frac{\text { Age variables }}{\text { Dams }}$} & & \multicolumn{7}{|c|}{ Diet groups } \\
\hline & & \multicolumn{3}{|c|}{ CTL } & & \multicolumn{3}{|c|}{ DLP } \\
\hline & & Mean & & SD & & Mean & & SD \\
\hline \multicolumn{9}{|l|}{ Murinometric } \\
\hline Length $(\mathrm{cm})$ & & 21.5 & & 1.41 & & 21 & & 0.00 \\
\hline BMI $\left(\mathrm{g} / \mathrm{cm}^{2}\right)$ & & 0.49 & & 0.03 & & 0.54 & & 0.03 \\
\hline Lee's index & & 0.24 & & 0.03 & & 0.26 & & 0.02 \\
\hline $\mathrm{CC}(\mathrm{cm})$ & & 11.50 & & 0.71 & & $11 \cdot 75$ & & 1.06 \\
\hline $\mathrm{AC}(\mathrm{cm})$ & & $13 \cdot 50$ & & 0.71 & & $14 \cdot 00$ & & 0.00 \\
\hline \multicolumn{9}{|l|}{ Organ weight (g) } \\
\hline Visceral fat & & 4.07 & & 0.98 & & $5 \cdot 21$ & & 0.69 \\
\hline Liver & & $13 \cdot 36$ & & 1.26 & & $16 \cdot 98^{\star \star \star}$ & & 0.40 \\
\hline \multirow[t]{3}{*}{ Gut } & & $15 \cdot 26$ & & 1.06 & & $13 \cdot 70$ & & 1.46 \\
\hline & \multicolumn{2}{|c|}{ CTL-M } & \multicolumn{2}{|c|}{ DLP-M } & \multicolumn{2}{|c|}{ CTL-F } & \multicolumn{2}{|c|}{ DLP-F } \\
\hline & Mean & SD & Mean & SD & Mean & SD & Mean & SD \\
\hline \multicolumn{9}{|l|}{ Pups $30 \mathrm{~d}$} \\
\hline \multicolumn{9}{|l|}{ Murinometric } \\
\hline Length $(\mathrm{cm})$ & $16 \cdot 37$ & 0.63 & $16 \cdot 62$ & 0.75 & $15 \cdot 75$ & 0.50 & $16 \cdot 25$ & 0.50 \\
\hline $\operatorname{BMI}\left(\mathrm{g} / \mathrm{cm}^{2}\right)$ & 0.44 & 0.01 & 0.42 & 0.01 & 0.44 & 0.01 & 0.41 & 0.02 \\
\hline Lee's index & 0.26 & 0.01 & 0.28 & 0.01 & 0.24 & 0.01 & 0.25 & 0.01 \\
\hline $\mathrm{CC}(\mathrm{cm})$ & 9.37 & 0.25 & 9.50 & 0.41 & $9 \cdot 25$ & 0.29 & 9.62 & 0.47 \\
\hline $\mathrm{AC}(\mathrm{cm})$ & $10 \cdot 25$ & 0.27 & $16 \cdot 00$ & 0.50 & 11.00 & 1.08 & $11 \cdot 37$ & 0.47 \\
\hline \multicolumn{9}{|c|}{ Organ weight (g) } \\
\hline Visceral fat & 0.99 & 0.20 & 1.02 & 0.11 & 0.79 & 0.09 & 1.27 & 0.34 \\
\hline Liver & 4.73 & 0.41 & $6 \cdot 27^{\star}$ & 0.76 & 4.60 & 0.21 & $5 \cdot 84$ & 0.21 \\
\hline Gut & 8.09 & 0.21 & 7.45 & 0.79 & 8.00 & 0.93 & 8.66 & 0.63 \\
\hline \multicolumn{9}{|l|}{ Pups $90 \mathrm{~d}$} \\
\hline \multicolumn{9}{|l|}{ Murinometric } \\
\hline Length (cm) & $24 \cdot 5$ & 0.46 & $25 \cdot 25$ & 0.50 & 22.00 & 0.81 & 21.50 & 0.57 \\
\hline $\operatorname{BMI}\left(\mathrm{g} / \mathrm{cm}^{2}\right)$ & 0.59 & 0.01 & 0.54 & 0.01 & 0.48 & 0.04 & 0.50 & 0.02 \\
\hline Lee's index & 0.24 & 0.01 & 0.21 & 0.01 & 0.22 & 0.02 & 0.23 & 0.01 \\
\hline $\mathrm{TC}(\mathrm{cm})$ & $13 \cdot 25$ & 0.64 & 9.50 & 0.41 & $9 \cdot 25$ & 0.29 & 9.62 & 0.47 \\
\hline $\mathrm{CC}(\mathrm{cm})$ & $15 \cdot 00$ & 0.81 & $16 \cdot 00$ & 0.70 & $12 \cdot 25$ & 0.50 & 14.5 & 0.57 \\
\hline \multicolumn{9}{|l|}{ Organ weight $(\mathrm{g})$} \\
\hline Visceral fat & 4.56 & 0.35 & $11.57^{\star \star *}$ & 2.73 & $4 \cdot 15$ & 3.29 & 3.01 & 0.77 \\
\hline Liver & $8 \cdot 20$ & 0.55 & $13 \cdot 06^{\star \star}$ & 1.77 & 12.05 & 0.56 & $14 \cdot 68^{\star \star}$ & 0.31 \\
\hline Gut & 11.93 & 0.84 & $14 \cdot 87^{\star \star}$ & 0.56 & 11.53 & 0.79 & $20 \cdot 69^{\star \star \star *}$ & 0.51 \\
\hline
\end{tabular}

$\mathrm{CC}$, chest circumference, AC, abdominal circumference; CTL-M, male pups fed by dams that consumed a control diet; DLP-M, male pups fed by dams that consumed a dyslipidaemic diet; CTL-F, female pups fed by dams that consumed a control diet; DLP-F, female pups fed by dams that consumed a dyslipidaemic diet.

Results obtained from two-way ANOVA followed by the Bonferroni post hoc test: ${ }^{*} P \leq 0.05,{ }^{* *} P \leq 0.01,{ }^{\star \star *} P \leq 0.001$.

VLDL levels (Fig. 5(e)) were observed in male and female pups from DLP dams at $30 \mathrm{~d}$ of age $(P \leq 0 \cdot 001)$ compared with those in pups from CTL dams $(P \leq 0.05)$. No differences were observed in the other measured lipid profile parameters at $30 \mathrm{~d}$ of age $(P>0.05)$, and no alteration was observed in the lipid profile in offspring at $90 \mathrm{~d}$ of age.

Pearson correlation analyses showed a significant negative correlation between HDL and Bacteroides spp. counts in DLP dams $(P \leq 0.05)$ (online Supplementary Fig. S2(a)). A strong negative correlation was observed between TAG and VLDL levels and Bacteroides spp. counts $(P \leq 0.05)$ in DLP male pups at $30 \mathrm{~d}$ of age (online Supplementary Fig. S2(b) and (c)). A significant negative correlation was observed between TAG levels and Lactobacillus spp. counts $(P \leq 0.05)$ in DLP female pups at $30 \mathrm{~d}$ of age (online Supplementary Fig. S2(d)), but a significant positive correlation between HDL levels and
Lactobacillus spp. counts was also found $(P \leq 0.05)$ (online Supplementary Fig. S2(e)).

\section{Histopathological evaluation of the intestine and liver}

Morphological assessment was performed by a histological analysis of intestinal cells as well as by morphometric analysis of the colon (Fig. 6). These analyses revealed that the DLP dams had villous atrophy (Fig. 6(a)). Similar results were observed in pups from DLP dams at 30 (Fig. 6(b)) and $90 \mathrm{~d}$ of age (Fig. 6(c)); both male and female pups showed inflammation, and only female pups presented epithelial villus atrophy. These findings were in accordance with the results of the morphometric analysis, which showed a decreased distance between the crypt and villi in pups from DLP dams (Fig. 6(d) and (e)). 

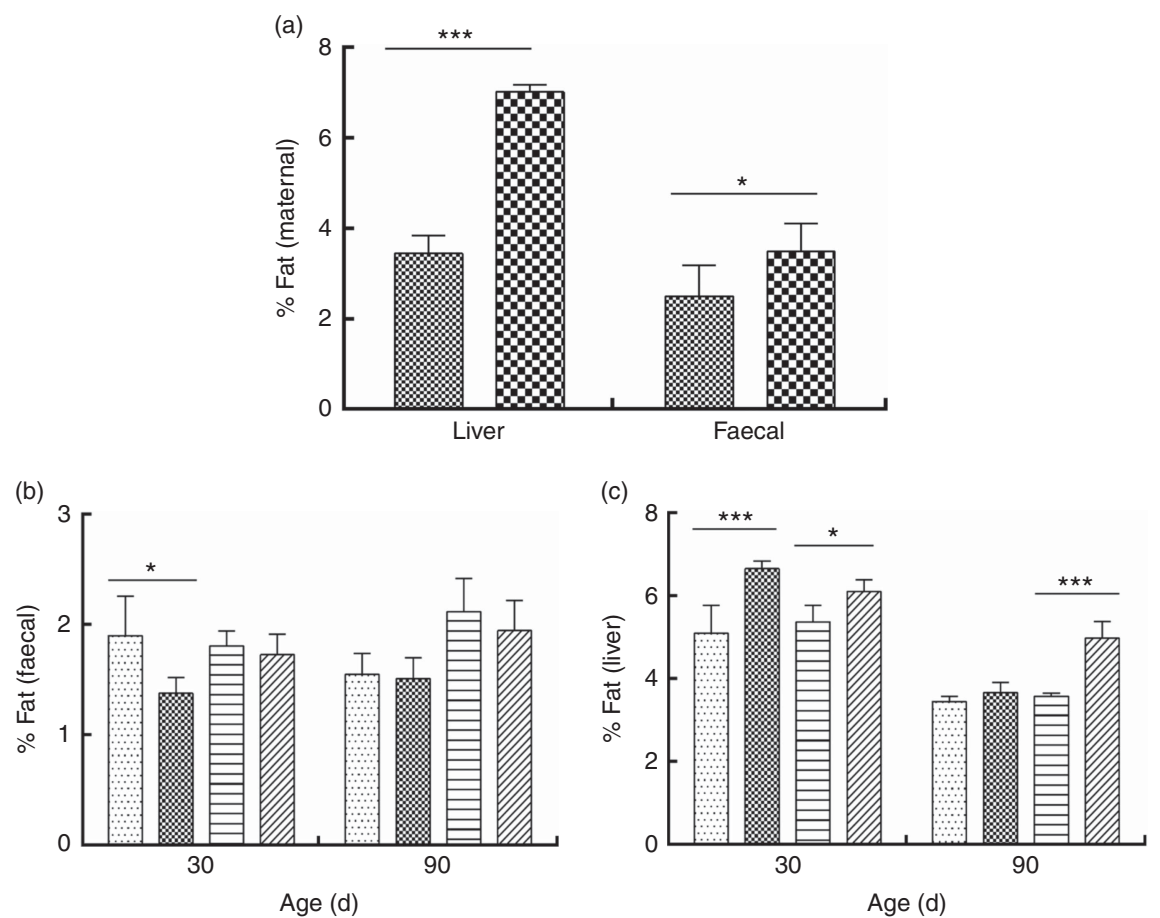

Fig. 3. Percentage of liver and faecal fat of dams (a) fed the control (CTL, 娄) or dyslipidaemic diet (DLP, , and their respective offspring (b) and (c). Two-way ANOVA followed by the Bonferroni post hoc test. Values are means, with standard deviations represented by vertical bars. ${ }^{*} P \leq 0.05,{ }^{* * *} P \leq 0.001$. Data are expressed as a percentage (\%). CTL-M (圆), male pups fed by dams that consumed a control diet; DLP-M (因), male pups fed by dams that consumed a dyslipidaemic diet; CTL-F (曰), female pups fed by dams that consumed a control diet; DLP-F (匂), female pups fed by dams that consumed a dyslipidaemic diet.

DLP dams showed fatty liver (Fig. 7(a)), which was confirmed by the higher histological scores of hepatic steatosis in this group (Fig. 7(d)). There was no change in the hepatic parenchyma of pups from either DLP or CTL dams at 30 and $90 \mathrm{~d}$ of age (Fig. 7(b) and (c)).

\section{Discussion}

The influence of a DLP diet rich in SFA and cholesterol on weight gain, lipid metabolism and liver and intestinal function of dams and their offspring was demonstrated in this study. The investigations focused on how this diet may influence physiological changes in each sex simultaneously from birth to adulthood, since the available literature has focused on only male pups, possibly in an attempt to avoid hormonal influence in female pups. The results of this study showed how maternal nutrition may modulate an array of metabolic parameters in offspring, reinforcing the idea that an adequate nutritional environment during pregnancy and lactation is critical for satisfactory offspring development ${ }^{(5,17)}$.

The DLP diet used in these experiments did not induce weight differences in the dams at the beginning and at the end of the pregnancy, although the DLP diet is more energetic than that of the CTL. These results may be justified by the lower consumption of DLP diet in most of the periods, possibly due to the satietyogenic effect caused by the higher fat content of this diet, indicating that a dyslipidaemic diet does not necessarily induce obesity ${ }^{(15,18)}$. Pups from DLP dams of both sexes had LBW, probably because of the imbalance in the fatty acid ratio ${ }^{(35)}$ and the reduction in energy content from protein, which is typical of a dyslipidaemic diet, and consequently, the low consumption of this nutrient from the indicated diet ${ }^{(36)}$. Regarding weight gain, from weaning to adulthood, there was a higher percentage of weight gain in pups from DLP dams compared with that in pups from CTL dams, which could be one of the negative impacts of dyslipidaemic diet consumption by dams ${ }^{(37-39)}$. Despite the higher weight gain throughout the experiment, both male and female pups from DLP and CTL dams presented similar Lee indexes and BMI. These findings were probably related to the fact that weight gain was proportional to animal length in both sexes during a specific growth phase ${ }^{(35)}$.

The results of this study also demonstrated that a dyslipidaemic diet during pregnancy and lactation negatively affects maternal hepatic function, causing alterations in liver parenchyma, accumulation of TAG, non-alcoholic fatty liver disease and hepatic injury. A maternal dyslipidaemic diet caused a higher percentage of liver fat in male and female pups from the DLP dams at $30 \mathrm{~d}$ of age. However, the maternal dyslipidaemic diet did not induce damage to liver parenchyma in the offspring of either sex over the short- or long-term. This fact may be related to the withdrawal of the negative stimulus exerted by the dyslipidaemic diet, since other studies showed that pups continuing to receive the same dyslipidaemic diet as their dams presented histological changes in the liver ${ }^{(40,41)}$. These results suggest that pups may have developed additional complications (other than hepatic steatosis) in the liver, such as the development of hypertension, which causes weight gain in this organ. A previous study observed that male pups from DLP 


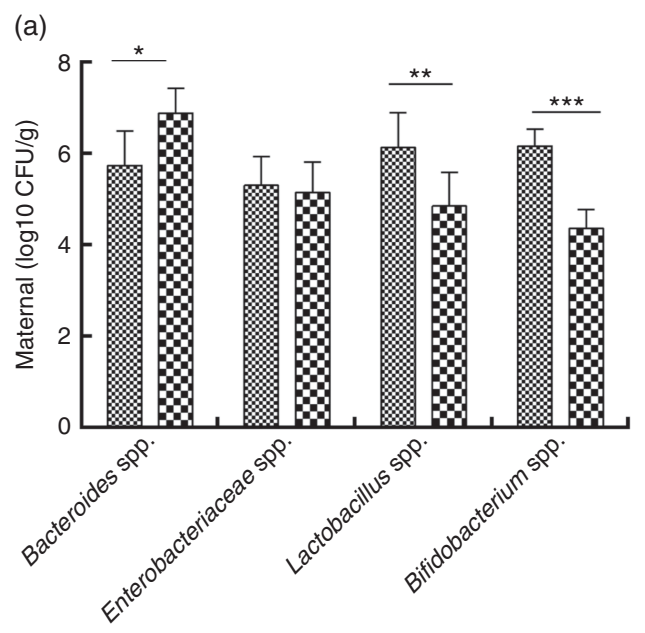

(b)

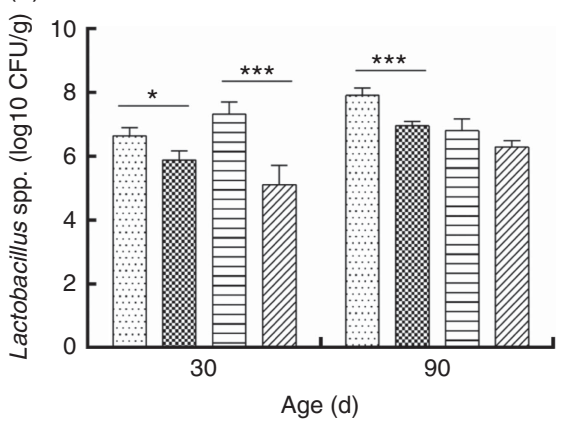

(d)

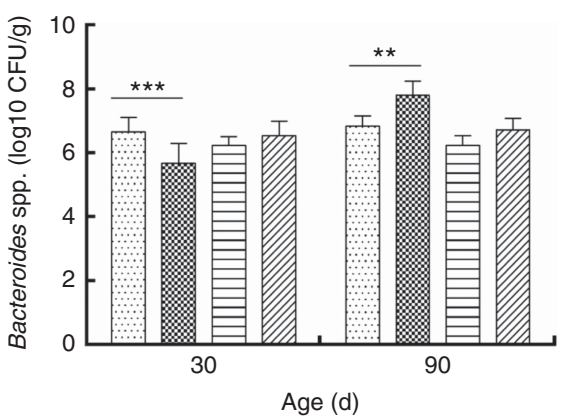

(c)

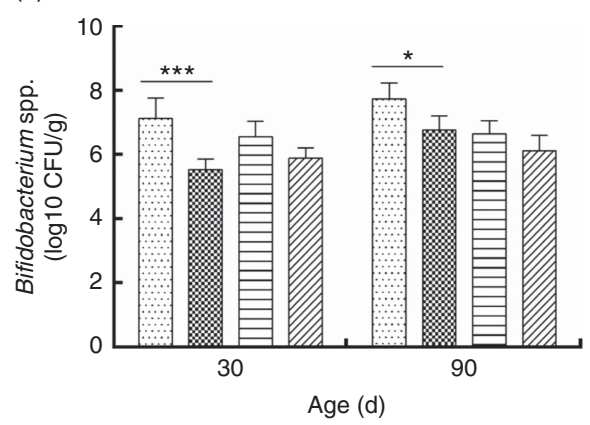

(e)

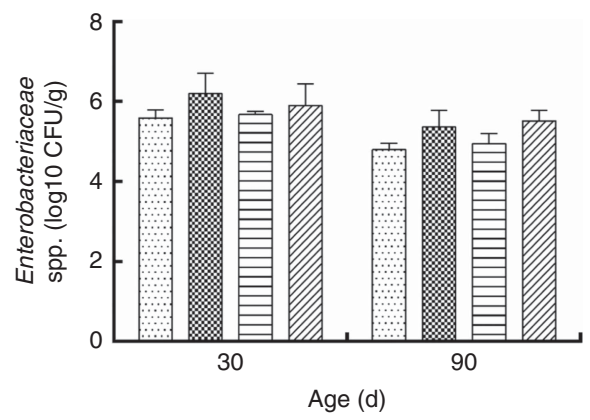

Fig. 4. Counts of Enterobacteriaceae, Bacteroides spp., Lactobacillus spp. and Bifidobacterium spp. in faeces of dams (a) fed a control diet (CTL, 因) or dyslipidaemic diet (DLP, $\mathrm{B}$ ) and in their respective offspring (b-e). Two-way ANOVA followed by the Bonferroni post hoc test. Values are means, with standard deviations represented by vertical bars. ${ }^{\star} P \leq 0.05,{ }^{\star \star} P \leq 0.01,{ }^{\star \star \star} P \leq 0.001$. CFU, colony-forming units. CTL-M (圆), male pups fed by dams who consumed a control diet; DLP-M (因), male pups fed by dams that consumed a dyslipidaemic diet; CTL-F (目), female pups fed by dams that consumed a control diet; DLP-F (שת) , female pups fed by dams that consumed a dyslipidaemic diet.

dams presented increased blood pressure and probably increased hydrostatic pressure, causing vascular oedema and vasodilation in hepatic veins $^{(35)}$.

The percentage of liver fat decreased throughout the life of the pups from DLP and CTL dams, which may be directly associated with hepatic steatosis going undetected in the histological analysis as well as with the similar faecal fat excretion among pups at $90 \mathrm{~d}$ of age. These results may also be associated with the fact that offspring from DLP dams returned to a normal diet with lower saturated fat and cholesterol intake or even that a maternal dyslipidaemic diet may not influence the long-term fat storage and excretion in offspring. However, the developmental-associated events occurring between 30 and $90 \mathrm{~d}$ of age may have masked the possible alterations that occurred at $30 \mathrm{~d}$, which should also be considered. Apparently healthy rats at $90 \mathrm{~d}$ of age could be more sensitive to developing metabolic disorders later in life ${ }^{(18,42)}$, as shown in studies in which maternal malnutrition ${ }^{(42-44)}$ and maternal dyslipidaemia ${ }^{(18)}$ have impacted health complications in the young adult period, in addition to showing a relationship between fetal nutrition and central control of energy balance and propensity for obesity in adult life, which is associated with an increase in the development of adipose tissue and hypertension ${ }^{(18,42,44)}$.

The pregnancy period alone causes alterations in various systems, including the maternal microbiome, with impacts on 
(a)

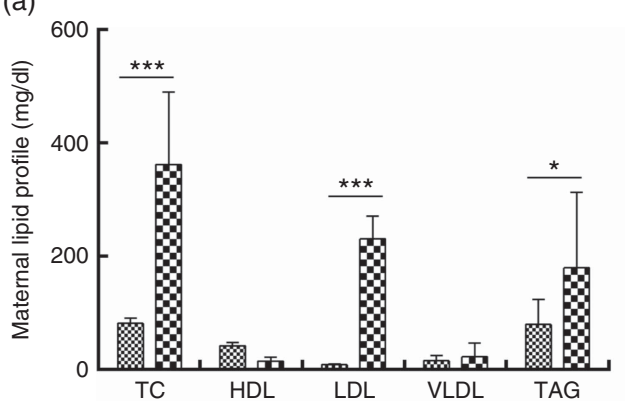

(c)

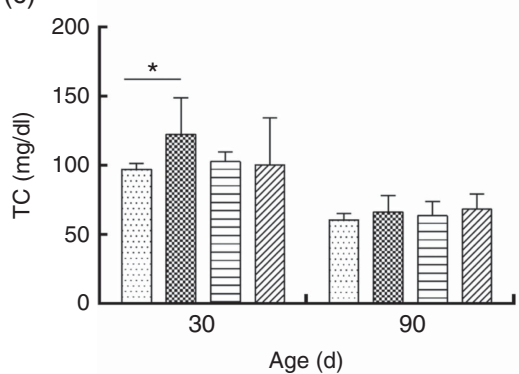

(e)

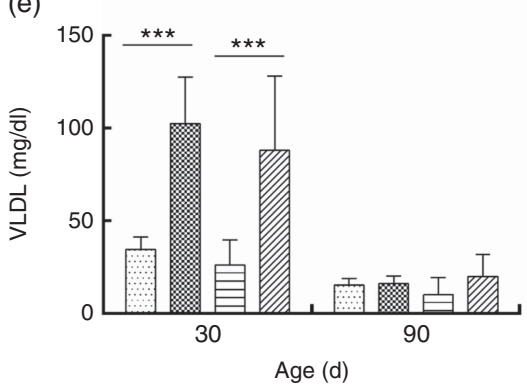

(b)

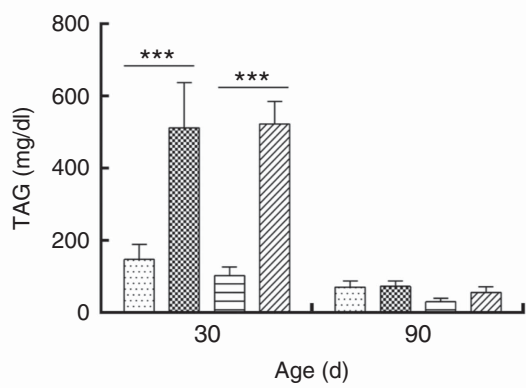

(d)

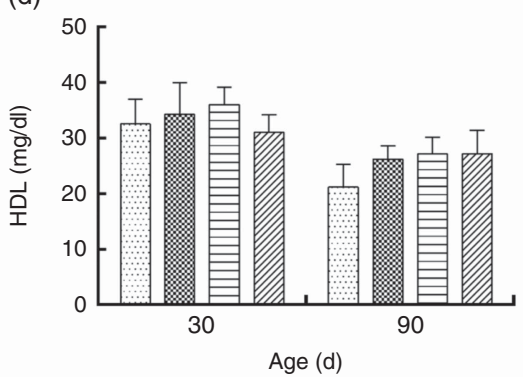

(f)

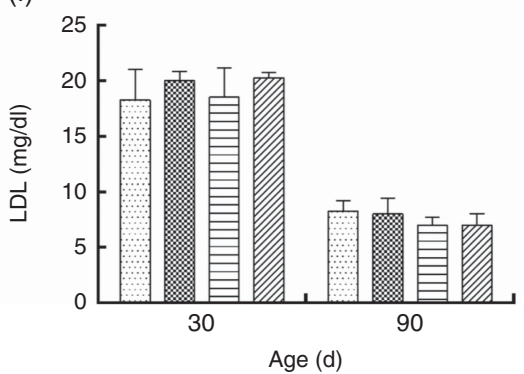

Fig. 5. Lipid profile of dams fed a control diet (CTL, $\mathrm{B}$ ) or dyslipidaemic diet (DLP, $\mathrm{B}$ ) (a) and their respective offspring (b-f) at 30 and $90 \mathrm{~d}$ old. Two-way ANOVA followed by the Bonferroni post hoc test. Values are means, with standard deviations represented by vertical bars. ${ }^{*} P \leq 0.05,{ }^{* * *} P \leq 0.001$. TC, total cholesterol. CTLM (圆), male pups fed by dams that consumed a control diet; DLP-M (国), male pups fed by dams that consumed a dyslipidaemic diet; CTL-F (目), female pups of dams that consumed a control diet; DLP-F (ש्Z), female pups form dams that consumed a dyslipidaemic diet. To convert TAG in $\mathrm{mg} / \mathrm{dl}$ to $\mathrm{mmol} / \mathrm{l}$, multiply by 0.0113 ; to convert TC, HDL, VLDL and LDL to $\mathrm{mmol} / \mathrm{l}$, multiply by 0.0259 .

the composition of intestinal microbiota of offspring ${ }^{(11,12)}$. Diet, as an external environmental factor, could also influence these alterations. The available literature reports that a diet rich in saturated fat may induce changes in intestinal microbiota, primarily dysbiosis, in mice ${ }^{(25,45)}$. The maternal DLP diet increased Bacteroides spp. faecal counts in dams. The Bacteroides genus has been shown to have affinity for substrates rich in saturated fat and animal origin proteins ${ }^{(46,47)}$. A high faecal population of Bacteroides spp. has also been associated with diarrhoea episodes $^{(48)}$. The highest counts of Bacteroides spp. were observed in the pups from DLP dams at $90 \mathrm{~d}$ of age. However, the maternal DLP diet did not increase the counts of Enterobacteriaceae in offspring throughout the monitored experimental period, probably because the intestine of these animals did not provide an ideal environment ( $\mathrm{pH} \mathrm{6-7)} \mathrm{for} \mathrm{the} \mathrm{growth}$ of these bacteria. An early study reported that rats fed a DLP diet present an intestinal $\mathrm{pH}$ between 8 and $9^{(15)}$.

DLP diet consumption caused a reduction in faecal counts of Lactobacillus spp. and Bifidobacterium spp. in dams and male pups at both 30 and $90 \mathrm{~d}$ of age. Our results indicate that male pups were more sensitive to changes in the counts of Bifidobacterium spp. and Bacteroides spp. induced by a maternal DLP diet compared with female pups. Testosterone, oestradiol and progesterone have been shown to influence metabolic pathways of gut microbiota, and these alterations could be related to sexual dimorphism, since males are typically more susceptible to these effects than females. A study relating sex to intestinal microbiota showed that testosterone modulated the faecal populations of Lactobacillus spp. in mice, where non-castrated males had higher counts compared with female or castrated male rats ${ }^{(49)}$. However, possible protective mechanisms in female rats to decrease this sensitivity have not been clarified ${ }^{(50)}$.

DLP consumption during pregnancy and lactation caused intestinal dysbiosis in dams and offspring of both sexes both at 30 and $90 \mathrm{~d}$ of age. This change in faecal microbiota composition possibly compromised intestinal epithelial integrity and caused a reduction in villi size that could induce complications 
(a)

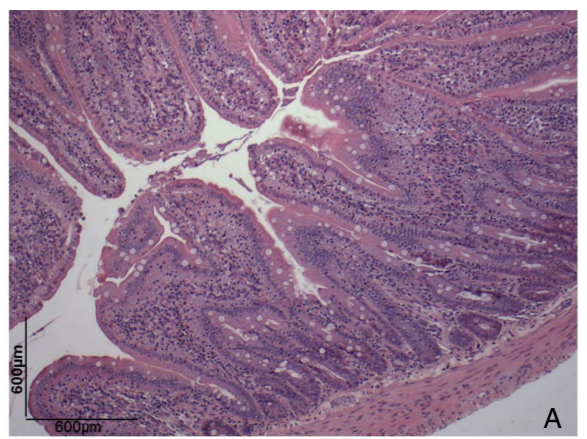

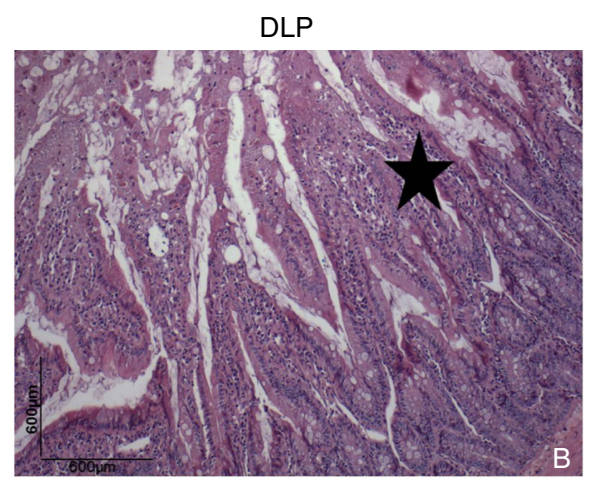

(b)

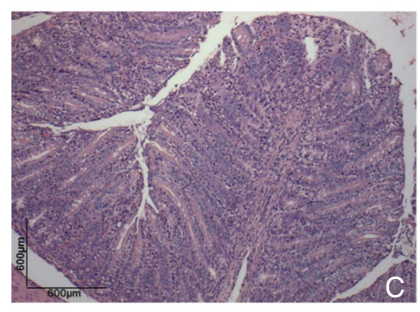

(c)

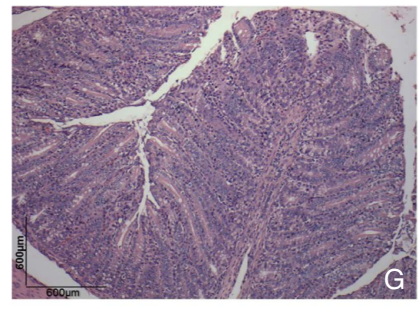

(d)

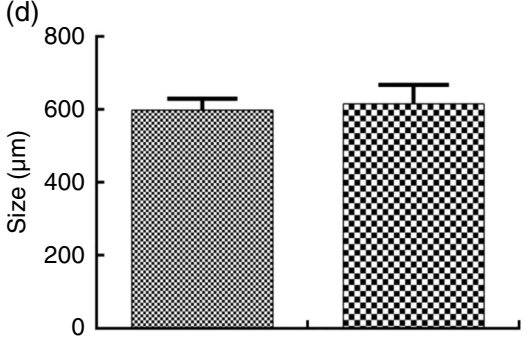

CTL-F

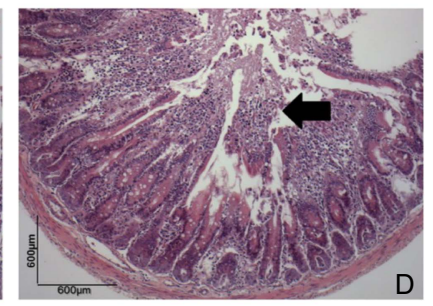

DLP-M

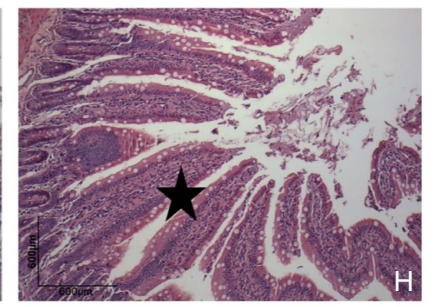

CTL-F
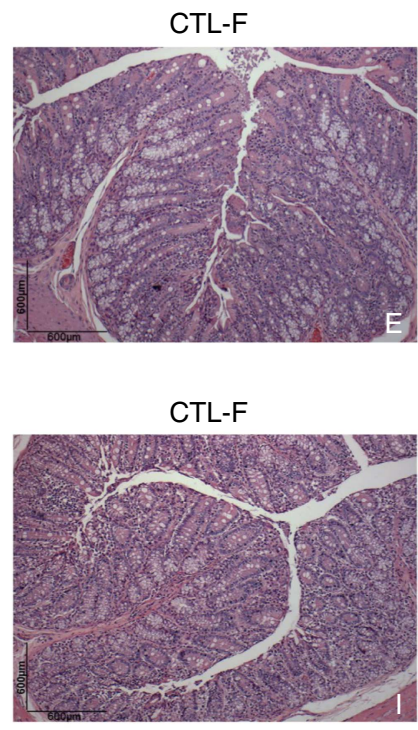

(e)

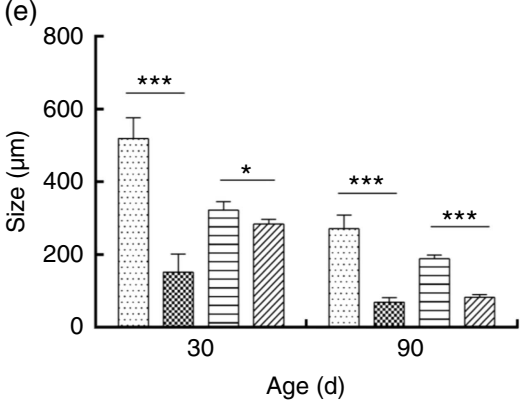

Fig. 6. Histology (a) of dams fed a control diet (CTL, R) or dyslipidaemic diet (DLP, $\mathrm{B}$ ) and their respective offspring at 30 (b) and $90 \mathrm{~d}$ of age (c) and morphometry of the colon of dams (d) and their respective pups (e) at 30 and $90 \mathrm{~d}$ of age. Arrow = mononuclear infiltrate. Star = villous atrophy. $t$ test. Values are means, with standard deviations represented by vertical bars. ${ }^{*} P \leq 0.05,{ }^{* * *} P \leq 0.001$. CTL-M (圆), male pups fed by dams that consumed a control diet; DLP-M ( $\$$ ), male pups fed by dams that consumed a dyslipidaemic diet; CTL-F (目), female pups fed by dams that consumed a control diet; DLP-F (四), female pups fed by dams that consumed a dyslipidaemic diet.

in nutrient absorption ${ }^{(51)}$. Such damage possibly occurred because the DLP diet increases the production of pro-inflammatory cytokines (IL-6 and TNF- $\alpha$ ) involved in the onset of damage to intestinal parenchymal tissue ${ }^{(52)}$.

Offspring of Japanese macaque primates (Macaca fuscata) fed a high-fat maternal diet showed persistent changes in gut microbiota composition, with possible effects on offspring metabolism for up to 1 year ${ }^{(53)}$. Other studies have shown that high-fat diets are likely to stimulate the growth of pathogenic bacteria in the intestine (e.g. Bacteroides spp.), causing alterations in fatty acid metabolism and infection in the peritoneal cavity ${ }^{(47,54)}$.

Another interesting finding of this study was the tendency for offspring to restore the desired composition of intestinal microbiota altered by a maternal DLP diet. Notably, pups from DLP dams that received the CTL diet reconstituted their intestinal microbiota throughout life. The intestinal microbiota of younger pups were probably affected by their consumption of breast milk from DLP dams, which was possibly unbalanced 
(a)

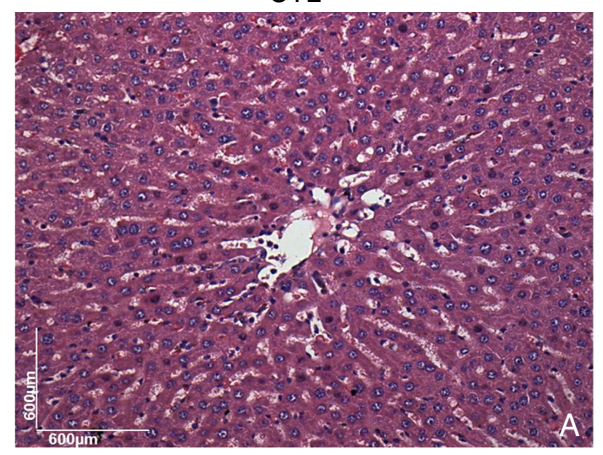

DLP

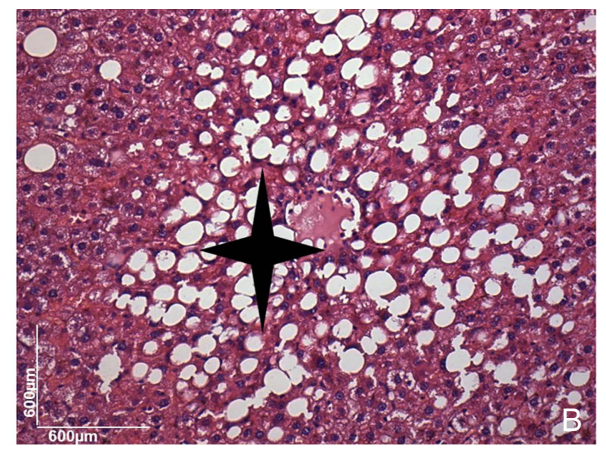

(b)

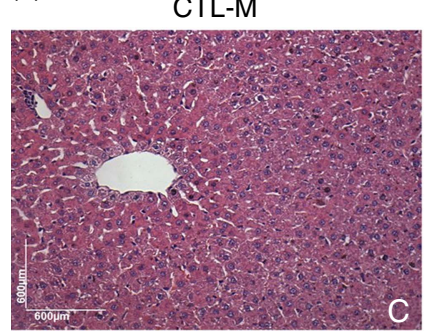

(c)
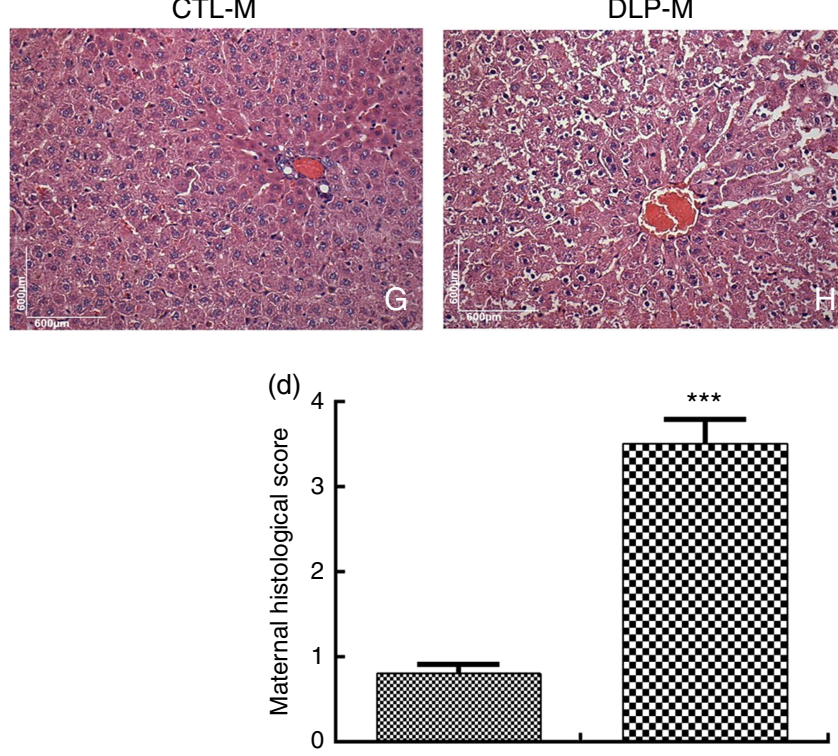

DLP-M

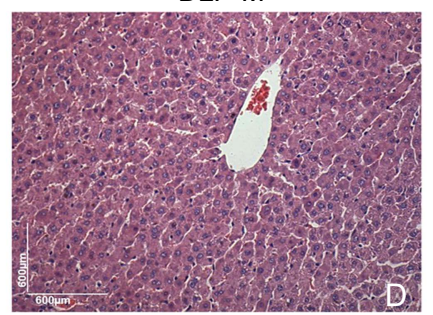

DLP-M

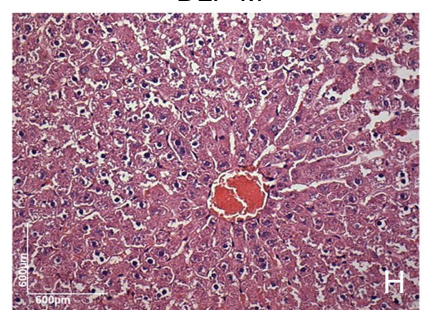

CTL-F

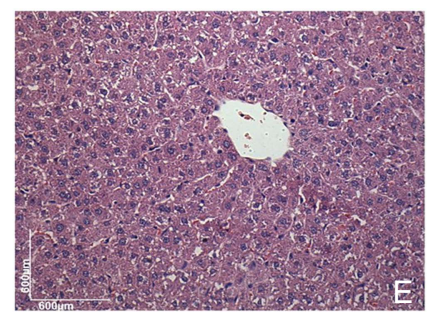

CTL-F
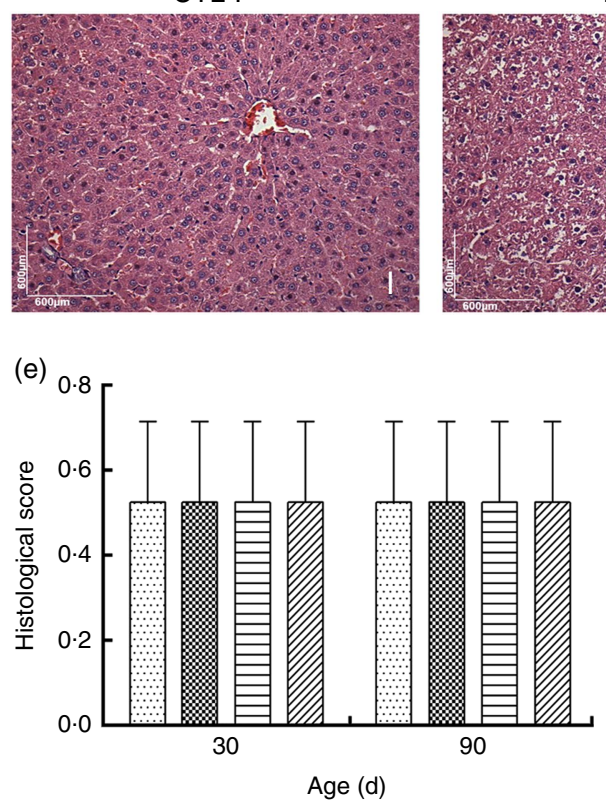

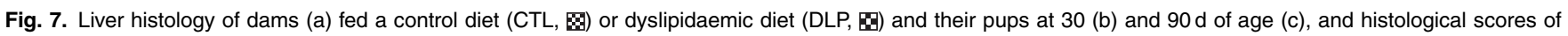
hepatic steatosis of the livers of dams (d) and their respective pups (e) at 30 and $90 \mathrm{~d}$ of age. $t$ test. Values are means, with standard deviations represented by vertical bars. ${ }^{* \star *} P \leq 0.001$. Four-pointed star $=$ hepatic steatosis. CTL-M (回), male pups fed by dams that consumed a control diet; DLP-M (R), male pups fed by dams that consumed a dyslipidaemic diet; CTL-F (目), female pups fed by dams that consumed a control diet; DLP-F (匂), female pups fed by dams that consumed a dyslipidaemic diet.

in lipid composition due to maternal ingestion of a dyslipidaemic diet during gestation and lactation ${ }^{(55)}$.

The increase in TAG levels and VLDL in offspring was agespecific but not sex-specific, as these parameters were altered at $30 \mathrm{~d}$ but not at $90 \mathrm{~d}$ of age in both male and female pups. These results indicate that DLP diet consumption alters the lipid composition of breast milk in rats ${ }^{(56,57)}$ and induces alterations in the serum lipid profile of pups in the short-term but not in the long-term ${ }^{(58)}$. This observation could be a consequence of the replacement of a DLP diet with a normal diet or of body homoeostatic regulation, as demonstrated in previous studies in which offspring from dyslipidaemic dams presented normal levels of TC, HDL, LDL and TAG from $90 \mathrm{~d}$ of age ${ }^{(18,26)}$. Another study showed that pups from dams that received a diet rich in saturated fat and nursed up to 
$14 \mathrm{~d}$ had LBW and elevated LDL-cholesterol levels due to the increase in levels of LDL receptor protein, a receptor responsible for the metabolism of LDL-cholesterol; its high levels are linked directly to cases of familial hypercholesterolaemia ${ }^{(36)}$.

The altered lipid profile and dysbiosis most prominently observed at $30 \mathrm{~d}$ but not $90 \mathrm{~d}$ of age reinforces the potential influence of an altered microbiome on host lipid metabolism ${ }^{(59)}$. The composition of gut microbiota has been reported to affect different molecular pathways associated with cardiovascular and cardiometabolic diseases, for example, trimethylamine/trimethylamine $\mathrm{N}$-oxide pathway, SCFA pathway and primary and secondary bile acid pathways. Nevertheless, bacterial translocation could contribute to the presence of bacterial products in systemic circulation, affecting the inflammatory state $^{(59,60)}$.

In addition, a normal lipid profile and greater resistance to changes in faecal microbiota in female pups from DLP dams at $90 \mathrm{~d}$ of age were probably influenced not only by dietary factors but also by the action of hormones (e.g. oestrogen) capable of increasing the expression of lipase-sensitive hormone and consequently, the lipolysis and stimulation of lipid oxidation with effects on lipid metabolism ${ }^{(61,62)}$.

The results of Pearson's correlation supported the hypothesis that the maternal diet during the perinatal period impacts not only the maternal faecal lipid profile and microbiota but also the offspring in a sex- and age-specific manner. These positive correlations were particularly observed in offspring at $30 \mathrm{~d}$ of age.

Due to the nutritional transition in the world population, studies with animal models involving fetal programming that were initially performed with nutrient-deficient diets ${ }^{(17,63)}$ are now directed to evaluate the effect of dyslipidaemic and obesogenic diets and their metabolic repercussions throughout life $\mathrm{e}^{(18,42,44)}$. It is important to emphasise that studies carried out to evaluate the impact of maternal dyslipidaemia in children and throughout their life are scarce because either ethical and temporal limitations or biochemical assessments of lipid profiles are often not part of the routine antenatal visits $^{(64)}$. In this sense, for a more complete understanding of the mechanisms related to developmental programming and with respect to the levels of scientific evidence in animal models as well as in clinical and epidemiological studies, the results of the present study may contribute to future recommendations addressed to maternal dyslipidaemia in the context of public health.

In conclusion, the results of this study demonstrate that the consumption of a dyslipidaemic diet during the gestational and lactational period is a preponderant factor for the appearance of alterations that negatively impact lipid metabolism, intestinal parenchyma and faecal microbiota in dams and offspring, especially in males over the short-term. These effects could be a consequence of a possible hormonal protective effect of females. Further studies are required to verify and explain how this hormonal action affects the short-term/long-term health/ disease status of offspring from dams fed a DLP diet.

\section{Acknowledgements}

The authors thank the Coordination for the Improvement of Higher Education Personnel (Coordenação de Aperfeiçoamento de Pessoal de Nível Superior - CAPES, Brazil) for a scholarship awarded to R. O. P. and CAPES (Brazil) and National Council for Scientific and Technological Development (Conselho Nacional de Desenvolvimento Científico e Tecnológico - CNPq, Brazil) for funding this study (grant no. 552098/2011-6).

R. O. P., J. L. d. B. A., E. L. d. S. and J. d. S. A. designed the study, conducted research in the literature, wrote the manuscript and reviewed the final version. R. O. P., P. P. L., A. F. A., R. d. A. P., J. L. P. d. C., L. T. T. and A. S. S. carried out the biological assay and research in the literature. R. O. P. and J. L. d. B. A. performed statistical analysis of the data.

The authors declare that there are no conflicts of interest.

\section{Supplementary material}

For supplementary material/s referred to in this article, please visit https://doi.org/10.1017/S0007114519000011

\section{References}

1. Steele EM, Baraldi LS, Louzada MLC, et al. (2016) Ultraprocessed foods and added sugars in the US diet: evidence from a nationally representative cross-sectional study. BMJ Open 6, e009892.

2. Cook JB, Hendrickson LM, Garwood GM, et al. (2017) Junk food diet-induced obesity increases D2 receptor auto inhibition in the ventral tegmental area and reduces ethanol drinking. PLOS ONE 12, e0183685.

3. Leech RM, Timperio A, Livingstone KM, et al. (2017) Temporal eating patterns: associations with nutrient intakes, diet quality, and measures of adiposity. Am J Clin Nutr 106, 1221-1230.

4. Gomez-Smith M, Karthikeyan S, Jeffers MS, et al. (2016) A physiological characterization of the cafeteria diet model of metabolic syndrome in the rat. Physiol Behav 167, 382-391.

5. Liska DJ, Cook CM, Wang DD, et al. (2016) Trans fatty acids and cholesterol levels: an evidence map of the available science. Food Chem Toxicol 98, 269-281.

6. Udenigwe CC \& Rouvinen-Watt K (2015) The role of food peptides in lipid metabolism during dyslipidemia and associated health conditions. Int J Mol Sci 16, 9303-9313.

7. Nascimento IB, Sales WB, Fleig R, et al. (2016) Excess weight and dyslipidemia and their complications during pregnancy: a systematic review. Rev Bras Saúde Matern Infant 16, 93-101.

8. Crew RC, Waddell BJ \& Mark PJ (2016) Maternal obesity induced by a 'cafeteria' diet in the rat does not increase inflammation in maternal, placental or fetal tissues in late gestation. Placenta 39, 33-40.

9. Morrison JL \& Regnault TRH (2016) Nutrition in pregnancy: optimizing maternal diet and fetal adaptations to altered nutrient supply. Nutrients $\mathbf{8}, 342-347$.

10. Romano-Keeler J \& Weitkamp J (2014) Material influences on fetal microbial colonization and immune development. Pediatr Res 77, 189-195.

11. Rodríguez L, Panader MI, Rodrigo S, et al. (2016) Liquid fructose in pregnancy exacerbates fructose-induced dyslipidemia in adult female offspring. J Nutr Biochem 32, 115-122.

12. Mueller NT, Bakacs E, Combellick J, et al. (2015) The infant microbiome development: mom matters. Trends Mol Med 21, 109-117.

13. Hu X, Wang T, Li W, et al. (2013) Effects of NS lactobacillus strains on lipid metabolism of rats fed a high-cholesterol diet. Lipids Health Dis 12, 67-79. 
14. Lau K, Srivatsav V, Rizwan A, et al. (2017) Bridging the gap between gut microbial dysbiosis and cardiovascular diseases. Nutrients 9, 859-876.

15. Batista K, Alves A, Lima M, et al. (2018) Beneficial effects of consumption of acerola, cashew or guava processing by-products on intestinal health and lipid metabolism in dyslipidaemic female Wistar rats. Br J Nutr 119, 30-41.

16. Cavallini DC, Suzuki JY, Abdalla DSP, et al. (2011) Influence of a probiotic soy product on fecal microbiota and its association with cardiovascular risk factors in an animal model. Lipids Health Dis 10, 126-135.

17. Castrogiovanni P \& Imbesi R (2017) The role of malnutrition during pregnancy and its effects on brain and skeletal muscle postnatal development. J Funct Morphol Kinesiol 2, 30-40.

18. Guimarães K, De Araújo E, Aquino J, et al. (2017) Effect of maternal dyslipidaemia on the cardiorespiratory physiology and biochemical parameters in male rat offspring. Br J Nutr 118, 930-941.

19. Lee H (2015) Impact of maternal diet on the epigenome during in utero life and the developmental programming of diseases in childhood and adulthood. Nutrients 7, 9492-9507.

20. Tain Y-L, Lin Y-J, Sheen J-M, et al. (2017) High fat diets sex-specifically affect the renal transcriptome and program obesity, kidney injury, and hypertension in the offspring. Nutrients 9, 357-376.

21. Langley-Evans SC, Bellinger L \& McMullen S (2005) Animal models of programming: early life influences on appetite and feeding behaviour. Matern Child Nutr 1, 142-148.

22. Rosenfeld CS (2015) Sex-specific placental responses in fetal development. Endocrinology 156, 3422-3434

23. Dudele A, Hougaard KS, Kjolby M, et al. (2017) Chronic maternal inflammation or high-fat-feeding programs offspring obesity in a sex-dependent manner. Int J Obes 41, 1420-1426.

24. Davis DJ, Hecht PM, Jasarevic E, et al. (2017) Sex-specific effects of docosahexaenoic acid (DHA) on the microbiome and behavior of socially-isolated mice. Brain Behav Immun 59, 38-48.

25. Porras D, Nistal E, Martínez-Flórez S, et al. (2017) Protective effect of quercetin on high-fat diet-induced non-alcoholic fatty liver disease in mice is mediated by modulating intestinal microbiota imbalance and related gut-liver axis activation. Free Radical Biol Med 102, 188-202.

26. Gray C, Vickers MH, Segovia SA, et al. (2015) A maternal high fat diet programs endothelial function and cardiovascular status in adult male offspring independent of body weight, which is reversed by maternal conjugated linoleic acid (CLA) supplementation. PLOS ONE 10, e0115994.

27. Chalvon-Demersay T, Blachier F, Tomé D, et al. (2017) Animal models for the study of the relationships between diet and obesity: a focus on dietary protein and estrogen deficiency. Front Nutr $\mathbf{4}, 5$.

28. Reeves PG, Nielsen FH \& Fahey GC Jr (1993) AIN-93 purified diets for laboratory rodents: final report of the American Institute of Nutrition ad hoc writing committee on the reformulation of the AIN-76A rodent diet. J Nutr 123, 1939-1951.

29. Folch J, Lees M \& Sloane Stanley GH (1957) A simple method for the isolation and purification of total lipides from animal tissues. J Biol Chem 226, 497-509.

30. Miles AA \& Misra SS (1938) The estimation of the bactericidal power of the blood. J Hygiene 38, 732-749.

31. Novelli ELB, Diniz YS, Galhardi CM, et al. (2007) Anthropometrical parameters and markers of obesity in rats. Lab Anim 41, 111-119.

32. Bernardis LL \& Patterson BD (1968) Correlation between 'Lee index' and carcass fat content in weanling and adult female rats with hypothalamic lesions. J Endocrinol 40, 527-528.
33. Erben U, Loddenkemper C, Doerfel K, et al. (2014) A guide to histomorphological evaluation of intestinal inflammation in mouse models. Int J Clin Exp Pathol 7, 4557-4576.

34. Kozak M (2009) "What is strong correlation?". Teach Stat 31, $85-86$.

35. Mayor RS, Finch KE, Zehr J, et al. (2015) Maternal high-fat diet is associated with impaired fetal lung development. Am J Physiol Lung Cell Mol Physiol 309, L360-L368.

36. Zinkhan EK, Zalla JM, Carpenter JR, et al. (2016) Intrauterine growth restriction combined with a maternal high-fat diet increases hepatic cholesterol and low-density lipoprotein receptor activity in rats. Physiol Rep $\mathbf{4}$, e12862

37. Kruse M, Seki Y, Vuguin PM, et al. (2013) High-fat intake during pregnancy and lactation exacerbates high-fat dietinduced complications in male offspring in mice. Endocrinology 154, 3565-3576.

38. Du Q, Hosoda H, Umekawa T, et al. (2015) Postnatal weight gain induced by overfeeding pups and maternal high-fat diet during the lactation period modulates glucose metabolis and the production of pancreatic and gastrointestinal peptides. Peptides 70, 23-31.

39. Simino LA, Fante T, Fontana MF, et al. (2017) Lipid overload during gestation and lactation can independently alter lipid homeostasis in offspring and promote metabolic impairment after new challenge to high-fat diet. Nutr Metab 14, 16-31.

40. Ji C, Dai Y, Jiang W, et al. (2014) Postnatal overfeeding promotes early onset and exaggeration of high-fat diet-induced nonalcoholic fatty livre disease through disordered hepatic lipid metabolism in rats. J Nutr Biochem 25, 1108-1116.

41. Perić Kačarević P, Grgié A, Snajder D, et al. (2017) Different combinations of maternal and postnatal diet are reflected in changes of hepatic parenchyma and hepatic TNF-alpha expression in male rat offspring. Acta Histochem 119, 719-726.

42. Venci RO, Ramos GB, Martins IP, et al. (2018) Malnutrition during late pregnancy exacerbates high-fat-diet-induced metabolic dysfunction associated with lower sympathetic nerve tonus in adult rat offspring. Nutr Neurosci (epublication ahead of print version 6 September 2018).

43. De Oliveira JC, Grassiolli S, Gravena C, et al. (2012) Early postnatal low-protein nutrition, metabolic programming and the autonomic nervous system in adult life. Nutr Metab (Lond) 9, 80.

44. Parlee SD \& MacDougald OA (2014) Maternal nutrition and risk of obesity in offspring: the Trojan horse of developmental plasticity. Biochim Biophys Acta Mol Basis Dis 1842, 495-506.

45. Wang W, Zhao J, Gui W, et al. (2018) Tauroursodeoxycholic acid inhibits intestinal inflammation and barrier disruption in mice with non-alcoholic fatty liver disease. Br J Pharmacol 175, 469-484.

46. Wu GD, Chen J, Hoffmann C, et al. (2011) Linking long-term dietary patterns with gut microbial enterotypes. Science $\mathbf{3 3 4}$, 105-108.

47. De Filippis F, Pellegrini N, Laghi L, et al. (2016) Unusual subgenus associations of faecal Prevotella and Bacteroides with specific dietary patterns. Microbiome 4, 57-62.

48. Ramamurthy D, Pazhani GP, Sarkar A, et al. (2013) Case-control study on the role of enterotoxigenic Bacteroides fragilis as a cause of diarrhea among children in Kolkata, India. PLOS ONE 8, e60622.

49. Yurkovetskiy PA, Burrows L, Khan M, et al. (2013) Gender bias in autoimmunity is influenced by microbiota. Immunity 39, 400-412

50. García-Gómez E, González-Pedrajo B \& Camacho-Arroyo I (2013) Role of sex steroid hormones in bacterial-host interactions. Biomed Res Int 2013, 928290.

51. Sears CL, Geis AL \& Housseau F (2014) Bacteroides fragilis subverts mucosal biology: from symbiont to colon carcinogenesis. J Clin Invest 124, 4166-4172. 
52. Chen Y, Lai L, Zhang H, et al. (2016) Effect of artesunate supplementation on bacterial translocation and dysbiosis of gut microbiota in rats with liver cirrhosis. World $J$ Gastroenterol 22, 2949-2959.

53. Ma J, Prince AL, Bader D, et al. (2014) High-fat maternal diet during pregnancy persistently alters the offspring microbiome in a primate model. Nat Commun 5, 3889.

54. Higashimura Y, Nailto Y, Takagi T, et al. (2016) Protective effect of agaro-oligosaccharides on gut dysbiosis and colon tumorigenesis in high-fat diet-fed mice. Am J Physiol Gastrointest Liver Physiol 310, G367-G375.

55. Priego T, Sánchez J, García AP, et al. (2013) Maternal dietary fat affects milk fatty acid profile and impacts on weight gain and thermogenic capacity of suckling rats. Lipids $\mathbf{4 8}, 481-495$.

56. Rodríguez-Cruz M, Sánchez R, Bernabe-Garcia M, et al. (2009) Effect of dietary levels of corn oil on maternal arachidonic acid synthesis and fatty acid composition in lactating rats. Nutrition 25, 209-215.

57. Purcell RH, Sun B, Pass LL, et al. (2011) Maternal stress and high-fat diet effect on maternal behavior, milk composition, and pup ingestive behavior. Physiol Behav 104, 474-479.
58. Kojima S, Catavero C \& Rinaman L (2016) Maternal high-fat diet increases independent feeding in pre-weanling rat pups. Physiol Behav 157, 237-245.

59. Tang WHW, Kitai T \& Hazen SL (2017) Gut microbiota in cardiovascular health and disease. Circ Res 120, 1183-1196.

60. Lippi G, Danese E, Mattiuzzi C, et al. (2017) The intriguing link between the intestinal microbiota and cardiovascular disease. Semin Thromb Hemost 43, 609-613.

61. Cooke PS \& Naaz A (2004) Role of estrogens in adipocyte development and function. Exp Biol Med 229, 1127-1135.

62. Jelenik $T$ \& Roden M (2013) How estrogens prevent from lipid-induced insulin resistance. Endocrinology $\mathbf{1 5 4}$ 989-992.

63. Barros KMFT, Manhães-De-Castro R, Lopes-De-Souza S, et al. (2006) A regional model (Northeastern Brazil) of induced malnutrition delays ontogeny of reflexes and locomotor activity in rats. Nutr Neurosci 9, 99-104.

64. Geraghty AA, Alberdi G, O'Sullivan EJ, et al. (2016) Maternal blood lipid profile during pregnancy and associations with child adiposity: findings from the ROLO study. PLOS ONE 11, e0161206. 